\title{
How Taxes and Real Wage Inflexibility Interact to Make Trade Deficits Addictive: the Tertiary and Quaternary Burdens and Benefits of a Transfer
}

\author{
Edward Tower Victor Yifan Ye \\ Duke University Duke University \\ January 9, 2016
}

ERID Working Paper Number 203

This paper can be downloaded without charge from the Social

Science Research Network Electronic Paper Collection:

http://ssrn.com/abstract=2718407

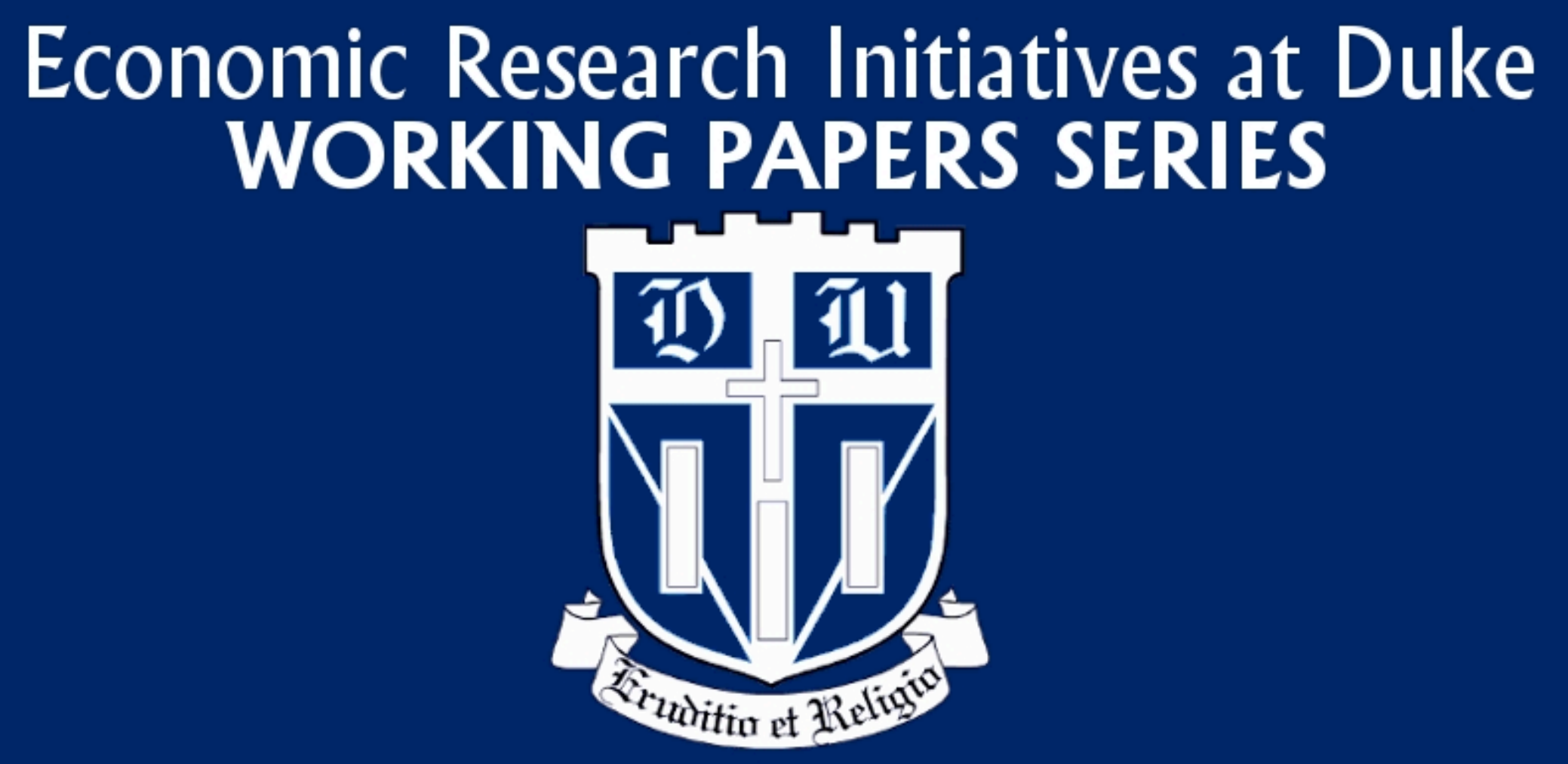


January 9, 2016 edition

\title{
How Taxes and Real Wage Inflexibility Interact to Make Trade Deficits Addictive: the Tertiary and Quaternary Burdens and Benefits of a Transfer ${ }^{i}$
}

By Edward Tower, tower@duke.edu, Professor of Economics at Duke University and 2015

Visiting Professor at Chulalongkorn University and Nanyang Technological University

and

Yifan (Victor) Ye, yifan.ye@duke.edu, Candidate for the MS degree in the Statistics and Economic Modeling program (MSEM) at Duke University.

PREPARED FOR THE SINGAPORE ECONOMIC REVIEW COLLECTION IN REMEMBERANCE OF RONALD I MCKINNON. This paper is preliminary and we eagerly seek comments.

\begin{abstract}
Previous articles on the transfer problem pay scant attention to the problems caused by the distortionary taxation that extracts the gift from the donor nation or the cut in distortionary taxation that bestows the gift to the recipient nation. When combined with inflexibility in the real wage these changes in taxation and the transfer itself impose a considerable burden to the donor matched by a considerable blessing to the recipient. We explore these effects, and conclude that "The Great Rebalancing" between the US and China needed to cure the US trade deficit, i.e. to eliminate the transfer that China is making to the US may bestow a big burden on the US matched by a big blessing for China.
\end{abstract}

\section{In Memory of Professor Ronald McKinnon}

Tower's association with Professor McKinnon consists of walking him to the MTA station at Harvard Square and trying to say something not monumentally stupid, when Tower was a grad student and McKinnon had just delivered a seminar. We have tremendous admiration for the Princeton study McKinnon wrote with Oates (1966), an early contribution to the monetary approach to the balance of payments, as well as for McKinnon's subsequent work on international adjustment, the transfer problem, and the currency in which assets and liabilities are denominated.

\section{Why Care About Real Wage Inflexibility and the Transfer Problem?}

Milton Friedman (1953) claimed in his "The Case for Variable Exchange Rates" that the increase in nominal wage inflexibility in the $20^{\text {th }}$ century made the gold standard or any regime 
of fixed exchange rates much less workable than it had been in the $19^{\text {th }}$ century. The move to raise real minimum wage rates in various cities of the USA, and to increase them in line with the price level, both testify to the loss of money illusion in the wage setting process and a willingness of the political system to set real wages and let employment depend on the exogenously determined wage. For a cautionary commentary on the current minimum wage epidemic see The Economist (2015). Downward inflexibility of real wages makes restoring competitiveness hard, and such restoration is essential to eliminate trade deficits without misery. Thus, the time is ripe to analyze the transfer problem in the context of downward inflexible real wages.

Tax rates too have increased. Keynes wrote that " $25 \%$ taxation is about the limit of what is easily borne." (Mitchell, 2010).Tax rates have risen beyond that level. According to Joel Slimrod in a conversation in the Spring of 2015, the marginal welfare cost of taxation in the US for the kinds of taxes that are likely to be levied is around 35\%. Thus, it seems appropriate to investigate the impact of a transfer in the presence of downward inflexible wages and the distortionary taxation needed to finance the transfer. For some useful calculations of the marginal welfare cost of taxation see Judd (1987), Shoven and Whalley (1984), Stuart (1984), and Warlters and Auriol (2007).

Michael Pettis (2013) in his book The Great Rebalancing stresses that Europe needs Germany to reduce its trade surplus and Greece to reduce its deficit. He also stresses the difficulties of rebalancing trade between the USA and China. However, in his discussions of these issues he ignores the issues of distortionary taxation and real wage inflexibility. We stress the interaction of the two here.

The recent criticism by the IMF of the Greek bailout plan (BBC, 2015) stresses that with Greek debt approaching $200 \%$ of Greek GNP a thirty year window is essential to pay it off. Lacking in this analysis is recognition of the difficulties imposed by wage inflexibility and the distortionary taxation necessary to effect the transfer. Similarly, the benefit to Germany of having Greece pay its debt, is the debt multiplied by the marginal welfare cost of taxation plus one. As Germany is more heavily taxed than the US, the German marginal welfare cost of taxation is probably greater than $35 \%$. According to Pettis (2015) France was required to pay reparations to Germany after the Franco-Prussian War of 5 billion gold francs, nearly $23 \%$ of French 1870 GNP. The reparations were paid over a span of 5 years. It is questionable whether such a payment would be manageable today in light of already high rates of taxation, which would have to climb still higher, and labor market inflexibility.

The primary burden or blessing of a transfer is the loss or gain associated with the items transferred. The secondary impact is the additional impact associated with induced changes in relative prices. The tertiary impact is the additional impact associated with changed level of 
employment in the presence of real wage inflexibility. The quaternary impact is the additional impact associated with the changed level of distortionary taxation necessary to effect the transfer.

We consider a series of models to illustrate the impact of a transfer in the presence of real wage inflexibility and distortionary taxation. We are happy to email the Microsoft Excel spreadsheets to those who would like to have them.

\section{A Transfer from France to Germany with Identical and Homothetic Preferences in the Two Countries. Full Employment}

Here is our model to start the discussion.

- Germany, victorious in the Franco-Prussian war against France, demands and receives reparations from France equal to one percent of initial French GDP.

- The transfer is specified in bottles of wine.

- We define one bottle of wine as the amount that sells for one franc in the initial equilibrium.

- We define one toy as the number of playthings that sells for one franc in the initial equilibrium.

- Germany makes 100 toys per year.

- France makes 100 bottles of wine per year. Thus each country's output is 100 francs in the initial equilibrium.

- Germany has an aggregate homothetic utility function with initial consumption shares of the two goods of 0.5.

- France has an aggregate homothetic utility function with initial consumption shares of the two goods of 0.5 .

- The French adjust their monetary policy to keep the price of wine constant at 1 franc per bottle of wine.

- There are no capital flows, so the transfer paid to Germany equals the French trade surplus, the excess of French exports over French imports.

- The transfer of one percent of French GDP is financed by a lump sum tax in France and a lump sum subsidy in Germany.

- Labor is the only factor of production in both countries. The supply of labor is fixed. The wage is flexible in both France and Germany, so full employment is maintained.

- In both countries, all income is spent.

- Throughout this article, German wages are flexible, so German full employment prevails, and a German lump sum subsidy assures the transfer is spent. 
We linearize the model about the initial no-transfer equilibrium and take proportional changes using matrix methods in Microsoft Excel. Equilibrium is described in column 1 of Table 1 , labeled as Flexible French wage. The identical and homothetic tastes assumption means that relative prices do not change in response to the transfer. Because of this, the simulation results are the same regardless of the common elasticity of substitution assumed. The transfer of purchasing power from France to Germany moves the German budget constraint outward by $1 \%$ and the French budget constraint inward by $1 \%$. We measure changes in utility by equivalent variations in income. Thus French utility falls by $1 \%$ and German utility rises by $1 \%$. The mathematics of all the simulations discussed in the body of the article are laid out in the appendix. After we solved the model using matrix methods, we discovered that the solution was simple enough to find by hand. We report these solutions later in the paper.

\begin{tabular}{|c|c|c|c|c|c|c|c|}
\hline \multicolumn{8}{|c|}{$\begin{array}{l}\text { Table 1. A Transfer of } \mathbf{1 \%} \text { of French GDP to Germany. Consumpt } \\
\text { utility does not change when the transfer is financed by a VAT. } \\
\text { France's wine consumption share and Germany's toy consumpti } \\
\text { All numbers except elasticity of substitution in consumption, } \sigma \text {, } \\
\sigma \text { is same for both countries. } \\
\text { Decimal places are eliminated when all numbers are zero. }\end{array}$} \\
\hline Column & 1 & 2 & 3 & 4 & 5 & 6 & 7 \\
\hline Simulations & $\begin{array}{c}\text { Flexible } \\
\text { French } \\
\text { wage }\end{array}$ & $\begin{array}{c}\text { Frozen } \\
\text { French real } \\
\text { wage. Lump } \\
\text { sum taxation }\end{array}$ & $\begin{array}{r}\text { Froz } \\
\text { Transfe }\end{array}$ & $\begin{array}{l}\text { Fren } \\
\text { financ }\end{array}$ & & $\begin{array}{l}\text { ble } u \\
\text { rne } b\end{array}$ & abor \\
\hline $\begin{array}{l}\sigma \\
\text { Variables }\end{array}$ & all & all & 0 & 0.5 & 1 & 5 & 999 \\
\hline Price of toys & 0 & 0 & -2 & -2 & -2 & -2 & -2 \\
\hline French toy consumption & -1 & -1 & 0 & -0.5 & -1 & -5 & -999 \\
\hline German toy consumption & 1 & 1 & 0 & 0.5 & 1 & 5 & 999 \\
\hline French utility & -1 & -1 & 0 & -1 & -2 & -10 & -1998 \\
\hline German utility & 1 & 1 & 0 & 0 & 0 & 0 & \\
\hline French wine consumption & -1 & -1 & 0 & -1.5 & -3 & -15 & -2997 \\
\hline German wine consumption & 1 & 1 & 0 & -0.5 & -1 & -5 & -999 \\
\hline Wine production & 0 & 0 & 0 & -1 & -2 & -10 & -1998 \\
\hline French nominal wage paid & 0 & 0 & 0 & 0 & 0 & 0 & 0 \\
\hline French nominal disposable wage & 0 & 0 & -1 & -1 & -1 & -1 & -1 \\
\hline French consumer price index & 0 & 0 & -1 & -1 & -1 & -1 & -1 \\
\hline French real disposable wage & 0 & 0 & 0 & 0 & 0 & 0 & 0 \\
\hline
\end{tabular}

There is no difference between the French nominal wage paid and the French nominal disposable wage. Once we introduce a value added tax, VAT, in simulations 3-7 the distinction between wage paid and disposable wage becomes relevant. The wage paid is what is paid out 
per worker to the sole factor of production, labor, plus what is paid per worker in value added tax. The disposable wage is what each worker receives after payment of the tax. The gap between the two is the VAT.

\section{Identical and Homothetic Preferences in the Two Countries, Lump Sum Taxation, and the French Real Wage is Frozen.}

We change nothing in this model, except we assume that the French real wage is frozen and the supply of labor is perfectly elastic at the exogenously determined French real wage. The simulation results are described in column 2 of Table 1 . Interestingly, the demand conditions peg the level of employment. If the relative price of toys rises, French workers, dissatisfied with their shriveled real wage, flow out of the wineries, drying up wine production and buoying the relative price of wine back up to its initial level, where it supports the same level of employment as before. The transfer to Germany leaves relative prices unchanged. Since the transfer is financed by a lump sum tax, the French nominal wage does not change. Nor does the French real wage change. Nor does employment or output change. The effect of the transfer is the same as in the full employment case. Since relative prices do not change, the simulation results are the same regardless of the common elasticity of substitution in the utility functions.

When $\sigma$ is infinite, the two goods are a single good, and France will have relaxed lump sum taxes by enough to be fully employed, prior to the transfer. In this case, if France were to receive a transfer, wine output would not increase.

\section{Identical and Homothetic Preferences in the Two Countries, Value Added Taxation, and the Real French Disposable Wage is Frozen.}

Now we recognize that a VAT is levied in France in order to finance the transfer, and we combine this with the assumption that the French disposable (i.e. after tax) real wage is frozen by a perfectly elastic supply of labor at that real wage. The simulations are presented in columns 3-7 of Table 1.

We let the elasticity of substitution in consumption, $\sigma$, vary between 0 and 999 . In order to effect the transfer, $1 \%$ of French GDP must be taxed away. With the franc price of wine unchanged, this lowers the disposable wage by $1 \%$. This implies an incipient reduction of the French real wage by that same $1 \%$. In response to this reduction, labor flows out of wine production until the price of wine relative to toys rises by $2 \%$, which means that the price of toys relative to wine falls by $2 \%$. With all initial consumption shares at $50 \%$, this reduces the French CPI by $1 \%$, which is just enough to leave the French real wage unchanged. This price and wage movement is the same regardless of the elasticity values assumed. If the common 
elasticity is close to zero, the requisite change in relative price occurs with hardly any change in output.

Regardless of the elasticity of substitution assumed, there is no change in German utility. The proportional change in German utility is the sum of the proportional change in German income and the proportional fall in the German CPI. The Germans see the relative price of wine has risen by $2 \%$ and they initially spend half of their incomes on wine. This reduces their real incomes by $1 \%$, and the income transfer of $1 \%$ of German GDP just balances that loss to leave German utility unchanged. The idea is that at the new set of prices and incomes, Germans could buy the same bundle of goods as before, and for small changes in incomes and prices, the envelope theorem means that utility is unchanged.

As the elasticity gets larger, the more reduction in the quantity of wine produced is necessary in order to get the relative price of wine up by $2 \%$. Thus the more unemployment France suffers, and the more French utility declines. In the case of an infinite elasticity, i.e. with perfect substitutability of the two goods, there is only one good, so there is no way to get the relative price of toys to fall, and there is no way to maintain the real wage in France, so French wine stops flowing all together, and French employment drops to zero. That is reflected in the huge drop in wine production recorded in column 7 . Nothing ever falls by more than $100 \%$, so the numbers in that column should more precisely be interpreted as the ratio of the percentage change in the variable to the transfer expressed as a percent of GDP in the limit as the transfer percent approaches zero.

\section{Each Country Prefers its Own Good. Full Employment.}

Table 2 describes the effect of a transfer from France to Germany when each country prefers its own good. Again the utility function is homothetic, and initially each country's consumption share of its own good is 0.9. Columns 1-4 describe the full employment model. The higher is the elasticity of substitution, the less is the increase in the price of toys to clear the market. Germany relishes its secondary blessing as the relative price of toys rises, and France suffers a secondary burden for the same reason. In the limit as the elasticities approach infinity the secondary effects disappear. Germany's utility rises by the same amount as the transfer and France's falls by the same amount as well: 1 percent of GDP. The French nominal wage is unchanged and the French real disposable wage falls except in the limit as the elasticities become infinite, so the price of toys don't rise at all. The tax is lump sum so the change in the French real disposable wage is the same as the change in the French real wage paid. Each country consumes the bulk of its own production, so its consumption of the other country's good changes hardly at all. The relative price of toys rises, so German consumption of wine rises by a larger proportion than German consumption of toys, and French consumption of wine falls by a smaller proportion than French consumption of toys. 
The flexible wage simulations in columns 1-4 can be solved analytically to yield:

1. $P^{\wedge}=-R \#(1-2 \phi) /[2 \sigma \phi(1-\phi) D]$

2. $U_{F} \wedge=-R \# / D$

3. $U_{G} \wedge=R \# / D$

where the symbol " $\wedge$ " denotes proportional change, $\phi$ is the common initial consumption share of each country's spending on the good it produces, $1-\phi$ is the common initial consumption share of the import, $\sigma$ is the common elasticity of substitution in consumption, $R \#$ is the transfer to Germany expressed as a fraction of French wine production, $P$ is the relative price of toys, $U_{F}$ is French utility, $U_{G}$ is German utility, and

\section{4. $D=1+[1 / 2 \phi-1] / \sigma$}

with $\mathrm{D}>0$ for stability.

\section{Table 2. A Transfer of 1\% of French GDP to Germany. Each country prefers its own good.}

France's wine consumption share \& Germany's toy consumption shares are initially both 0.9 .

All numbers except elasticity of substitution in consumption, $\sigma$, are percent changes. $\sigma$ is same for both countries.

Decimal places are eliminated when all numbers are zero.

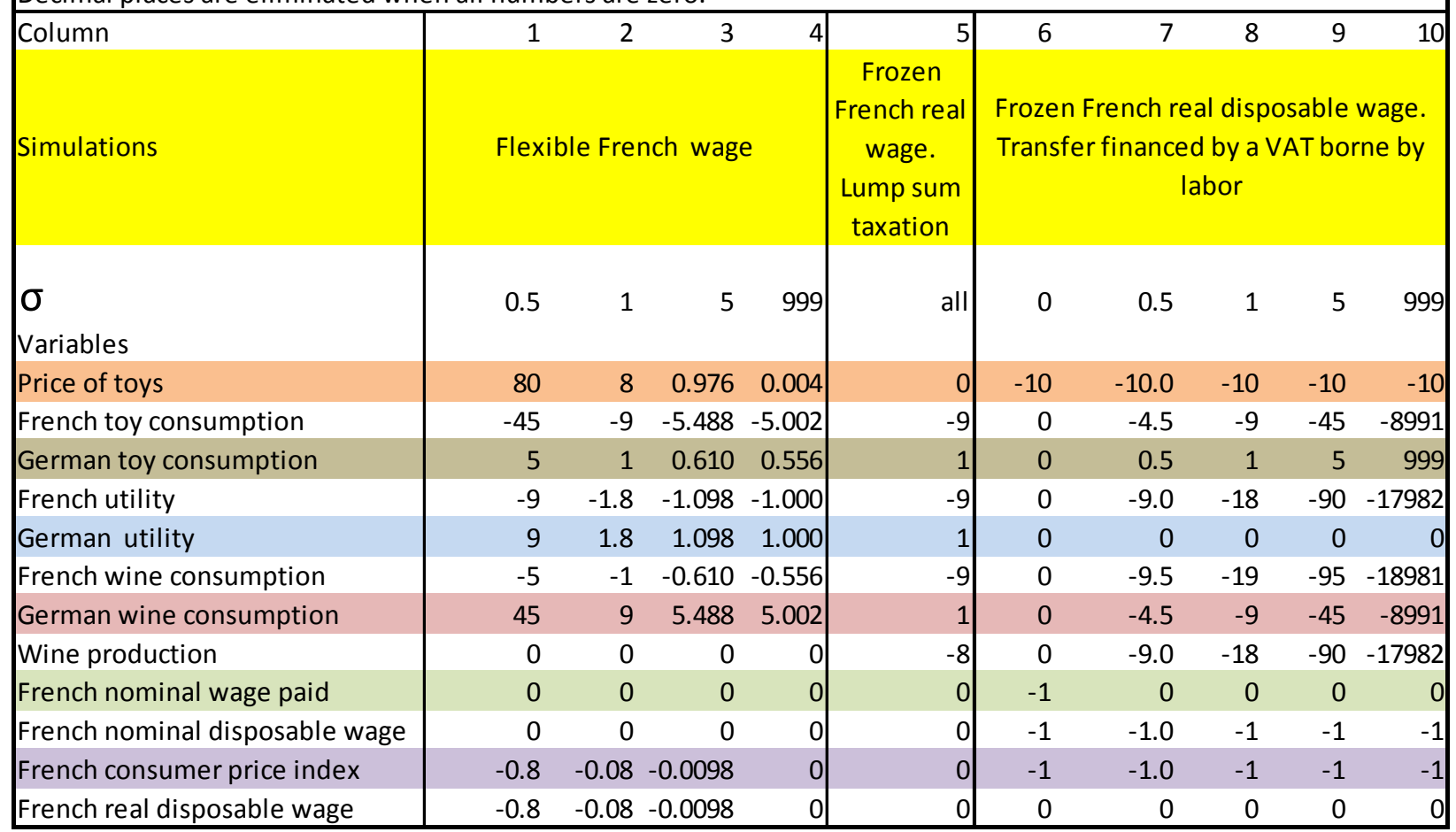

Note that when $\phi=0.5$ (identical tastes), $\mathrm{P}^{\wedge}=0$, and both countries utilities change by the amount of the transfer. This is also the case when $\sigma$ approaches infinity. Both are consistent with intuition. France loses more and Germany gains more when each country's consumption share of its own good is large. 


\section{Each Country Prefers its Own Good, Lump Sum Taxation, and the French Real Wage is Frozen.}

Column 5 of Table 2 describes the frozen real wage French economy when the tax to effect the transfer is lump sum. The only way for the French real wage to be constant is for the relative price of toys not to change at all. Thus the elasticity of substitution in consumption is irrelevant, and one simulation tells the story for all elasticities.

Since the relative price of toys is unchanged, Germany simply gains the amount of the transfer: one percent of GDP. To keep the relative price of toys constant, when the wine loving French are impoverished by the transfer, wine production, $\mathrm{W}$, must fall by 8 percent, causing French utility to fall by a total of 9 percent. German consumption of wine rises by $100 * 0.1 * .01=.1$ bottles. French consumption of wine falls by $100 * .9 * .09=8.1$ bottles, and French production falls by 8 bottles, to just match the change in world production. Thus the primary effect of the transfer is dwarfed by the tertiary effect.

The analytical solution for this model is

$$
\begin{aligned}
& \text { 5. } P^{\wedge}=0 \\
& \text { 6. } W^{\wedge}=(1-2 \phi) /(1-\phi) \\
& \text { 7. } U_{F}^{\wedge}=-R \# \phi /(1-\phi) \\
& \text { 8. } U_{G^{\wedge}}=R \# .
\end{aligned}
$$

This model is necessarily stable, because the supply of wine is infinitely elastic.

When $\phi=0.5$, preferences are identical and homothetic, so the utilities change by the amount of the transfer and French output does not change. When each country prefers its own $\operatorname{good}(\phi>0.5)$, French wine output has to fall, to keep pace with reduced wine demand.

In this case, if France initially suffers from unemployment, and a lump sum subsidy is granted, the relative price of wine will increase, generating more employment until full employment is achieved. Thus, assuming rational macro policy, France must be fully employed prior to the transfer.

\section{Each Country Prefers its Own Good, Value Added taxation, and the Real French Disposable Wage is Frozen.}

When the transfer is effected by a value added tax: at constant prices, French labor's disposable real wage falls by one percent. To keep the real wage constant the French CPI must 
fall by the same one percent. Since the French spend only 10 percent of their income on toys, the price of toys must fall by ten percent to effect the change. The Germans, elated by their receipt of the transfer, are depressed by the secondary burden that just balances it out, leaving the Germans with no change in utility. The French suffer from the interactions of the tertiary and quaternary burdens. In the limiting case of perfect substitution between the two goods (not shown in Table 2) all French wine production would cease, France would lose utility equal to 100 percent of GDP, and there would be no wine to transfer to Germany. As the elasticity shrinks down to zero, the drop in French wine production necessary to effect the relative price change of $10 \%$ falls to zero, and the French transfer of one percent of GDP is just balanced by the ten percent fall in the price of toys, leaving French utility unchanged.

When we solve the model analytically we see that the French CPI rises by the French consumption share of toys times the change in the toy price:

9. $C P I^{\wedge}=(1-\phi) P^{\wedge}$.

The proportional change in the French real disposable wage, FRDW, is the sum of the transfer as a proportion of wine output and the proportional change in the French CPI. Since FRDW must remain constant, we have:

10. $\mathrm{FRDW}^{\wedge}=-\mathrm{RH}-\left.\mathrm{CP}\right|^{\wedge}=0$.

From 9 and 10 the toy price falls by a multiple of the transfer:

11. $P^{\wedge}=-R \# /(1-\phi)$.

Since the French real disposable wage is constant, the change in French utility must equal the change in French wine output:

From the Appendix we have:

12. $W^{\wedge}=-R \# 2 \phi \sigma /(1-\phi)$

13. $U_{F}^{\wedge}=-R \# 2 \phi \sigma /(1-\phi)$

and

14. $U_{G} \wedge=0$.

The wine output falls by more, the larger the price change, the larger the share of each country's consumption of its own good, and the larger the elasticity of substitution, because increases in all three mean that the demand for wine induced by the transfer falls by more. 
The German toy output measured in francs changes by a proportion $\mathrm{P}^{\wedge}$. The German terms of trade effect as a proportion of toy production is $(1-\phi) \mathrm{P}^{\wedge}=-\mathrm{R} \#$. Germany receives a transfer as a proportion of its toy output measured at R\#. Thus, Germany's utility is constant.

In the special case where $\sigma=0$, the solution to the model is $U_{F}^{\wedge}=U_{G}{ }^{\wedge}=W^{\wedge}=0$.

The loss in French utility with the VAT is bigger than with the lump sum taxation so long as $\sigma$ exceeds 0.5 . This case is necessarily stable because the VAT is levied only when there is a transfer, so the stability condition is the same as for the lump sum taxation.

Assuming France has lump sum subsidies at its disposal, it will have achieved full employment prior to the transfer.

\section{A Donor Enriching Transfer and a Recipient Immiserizing Transfer}

Beladi (1990), Brecher and Bhagwati (1982), Bhagwati, Brecher, Hatta. (1983, 1984, 1985). and Chinchilinski $(1980,1983)$ have all developed paradoxes in which the donor is enriched by the process of donation. Beladi's is the closest to this paper as he assumes variable employment and even refers to the employment effect of a transfer as the tertiary effect of the transfer. His model assumes two goods, capital and labor in both sectors, a fixed factor in the agricultural sector as well, and an economy-wide wage rate which is fixed in units of the agricultural good (a throwback to Ricardo's thinking of wheat as the wage good). He finds that a transfer which simultaneously immiserizes the recipient and benefits the donor is possible. The analysis is complex and not easy to follow. To complement it we provide a more transparent analysis here.

We wonder whether there is yet another case of a donor enriching transfer or a recipient impoverishing transfer along the lines we have visualized here. We initially tried to find such a case within the context of the models developed so far in the paper. However, it does not happen. Consequently, we build a variant of our models here. We consider the model where there is lump sum taxation and the French real wage is frozen. As we saw from our earlier models this freezes all prices. The change in French real income, $Y_{F}$, which we define as identical to the change in French utility is:

15. $d Y_{F}=d U_{F}=d W-d R$,

where $\mathrm{W}$ and $\mathrm{R}$ are wine production and transfer expressed in francs. The change in French spending on wine is:

16. $d C_{W F}=f[d W-d R]$, 
where $f$ is the French marginal propensity to spend on wine out of income. The change in German spending on wine is:

17. $d C_{W G}=g^{*} d R$,

where $g$ is the German marginal propensity to spend on wine out of income. Setting the change in the supply of wine to the change in demand for wine:

18. $d W=f[d W-d R]+g^{*} d R$,

So:

19. $d W[1-f]=[g-f] d R$.

Thus,

20. $d W=d R[g-f] /[1-f]$.

The change in French utility is

21. $d U_{F}=d W-d R=d R[g-1] /[1-f]$.

Let's assume the French marginal propensity to spend on wine is less than 1 . Then, a German marginal propensity to spend on wine that is greater than 1 increases French wine output by enough to raise French utility.

In this case, France may not be fully employed prior to the transfer. This is because at the full employment level of French spending the relative price of toys may be so high that the real wage may be too low to support labor's demanded real wage.

Let's look at some special cases to see if this formula makes sense. When the French marginal propensity to consume wine is zero, the increased production of wine equals the German marginal propensity to consume wine, $g$, and it is obvious that the change in French utility is $g-1$. When $g=f$, there is no change in wine production and French utility falls by the amount of the transfer. The standard Keynesian multiplier is dG/(1-c), where dG is the change in the autonomous component of spending, and $\mathrm{c}$ is the marginal propensity to consume. Similarly, when a transfer occurs, the change in autonomous spending on French goods is $\mathrm{dR}[\mathrm{g}$ $\mathrm{f}]$, and to get the ultimate change in wine production we must divide by 1 minus the French marginal propensity to consume wine. Just as $c<0$ is the stability condition in the standard multiplier case, $\mathrm{f}<1$ is the stability condition here. 
If we change the sign of transfer, visualizing France as the recipient of the transfer after World War I, then we realize that under these same conditions, the recipient will be immiserized.

\section{Each country prefers the other country's good: Completing the set.}

For completeness sake, in Table 3, we consider the unorthodox case in which each country prefers the other country's good. Here again we have homothetic utility functions, with the share of income spent on the other country's good equal to 90 percent. When wages are flexible (columns 1-4), the relative price of wine rises, and the changes in utility shrink in absolute value by more, the lower are the elasticities of substitution. When the French real wage is frozen and the taxation is lump sum (column 5), relative price can't change and elasticities are irrelevant. Again Germany gains one percent from the transfer, with the secondary effect eviscerated. To keep the price of wine constant, French wine production must expand, so the tertiary blessing of the transfer blunts the primary burden for the French. Finally, with the VAT and with the French real disposable wage frozen (columns 6-10), the price of toys must fall by $1.11 \%$ to shrink the French CPI by one percent and leave the French real disposable wage constant. In other words the fall in the toy price just compensates the French worker for the transfer. It also compensates Germany for the transfer in the opposite way, leaving German utility unchanged. French utility falls not at all when the elasticities are zero, for in that case no output change is necessary to effect the desired price change, but as the elasticities rise, wine production must fall by more and in the special case of perfect substitution, all wine production ceases, and as with Table 2, French utility falls by 100 percent. 


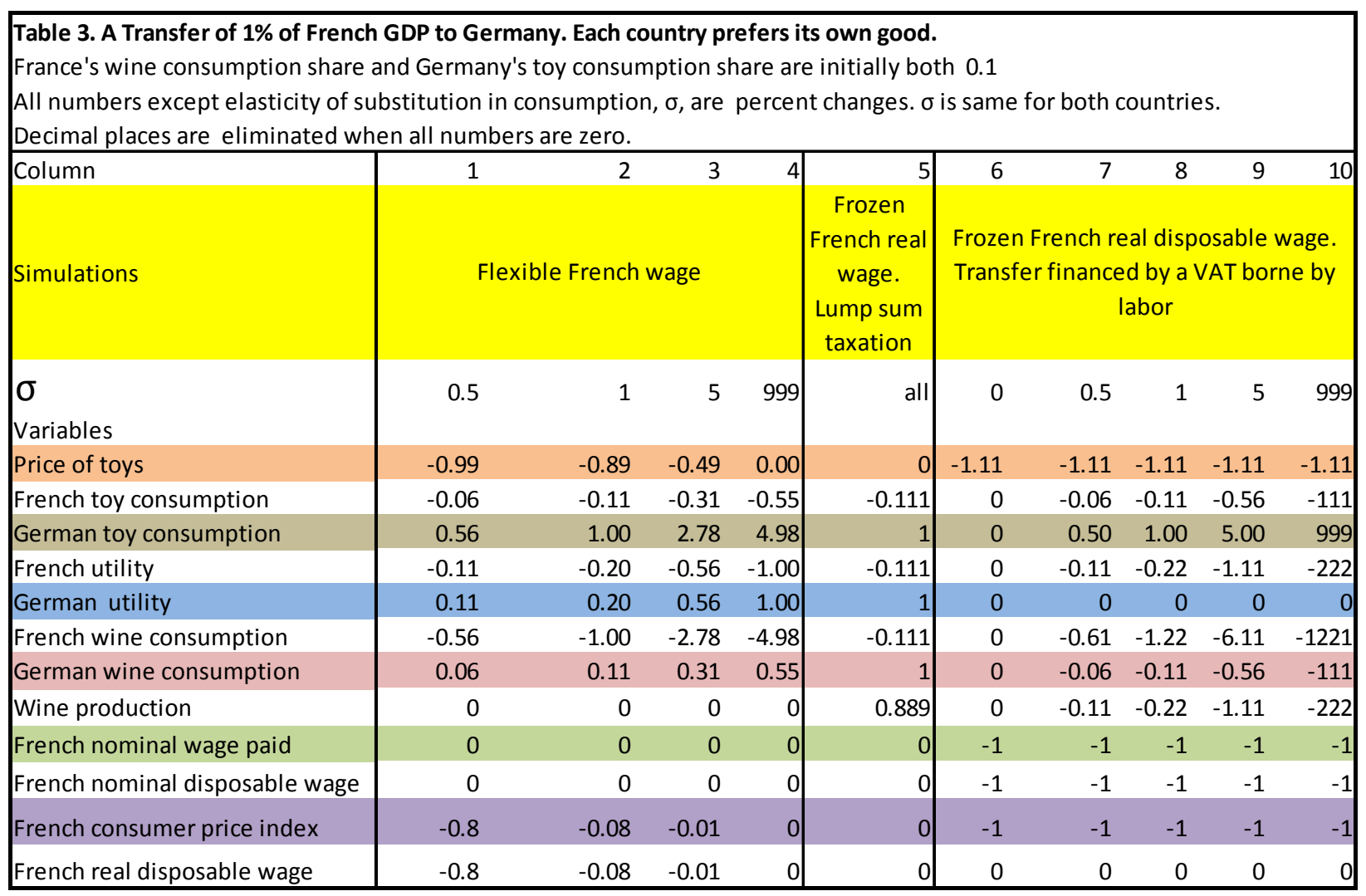

\section{So what?}

The numerical examples in this paper are intended to help the reader think clearly about the effects of transfers on a country with a frozen real wage, distorting taxation, and variable employment. We believe that in teaching the transfer problem these models are important benchmarks. We have picked extremely simple models in order to help readers wrap their minds around the mechanisms involved. We were delighted with the simplicity of the formula for the paradoxical donor-enriching or recipient-impoverishing transfer. Finally, we observe increasingly rigid real wages, and believe that this trend makes models with exogenously determined real wages increasingly relevant to descriptions of actual economies.

\section{Appendix: The Mathematics of All three Transfer Models}

All three of our models have three equations in common. Now we derive them.

$\mathrm{C}_{\mathrm{WF}} / \mathrm{C}_{\mathrm{TF}}$ depends on $\mathrm{P}$, where $\mathrm{C}_{\mathrm{WF}}$ is wine consumed by the French, $\mathrm{C}_{\mathrm{TF}}$ is toys consumed by the French. Notation carries over from the body of the article. Since we have identical and homothetic preferences, this translates to 
A1. $C_{W F}^{\wedge}-C_{T F}^{\wedge}=\sigma P^{\wedge}$

where the franc price of wine is frozen by French monetary policy, so $\mathrm{P}^{\wedge}$ is the proportional change in both the franc price of toys and the relative price of toys.

By analogy,

A2. $\mathrm{C}_{W G^{\wedge}}-\mathrm{C}_{\mathrm{TG}}^{\wedge}=\sigma \mathrm{P}^{\wedge}$

where $\mathrm{C}_{\mathrm{WG}}$ is wine consumed by Germany, and $\mathrm{C}_{\mathrm{TG}}$ is toys consumed by Germany.

French consumption spending, $\mathrm{C}_{\mathrm{WF}}+\mathrm{C}_{\mathrm{TF}} \mathrm{P}$, lies below French wine output, $\mathrm{W}$, by the amount of the transfer, $\mathrm{R}$, so $\mathrm{W}-\mathrm{C}_{\mathrm{WF}}-\mathrm{C}_{\mathrm{TF}} \mathrm{P}=\mathrm{R}$. $\phi$ is the share of the good each country produces in its own consumption, so $1-\phi$ is the consumption share of the import. We differentiate and divide by French output to get

A3. $W^{\wedge}-\phi C_{W F}^{\wedge}-(1-\phi)\left[C_{T F}^{\wedge}+P^{\wedge}\right]=d R /\left[P_{W W}\right]=R \#$.

The analogous equation for Germany's national income is $T^{*} \mathrm{P}-\mathrm{C}_{\mathrm{WG}}-\mathrm{C}_{\mathrm{TG}} * \mathrm{P}=-\mathrm{R}$, where $\mathrm{T}$ is German toy output. Differentiating, while remembering that initially French and German output values are the same and German output of toys is constant yields

A4. $\quad P^{\wedge}-(1-\phi) C_{W G}^{\wedge}-\phi\left[C_{T G}^{\wedge}+P^{\wedge}\right]=-d R /[P W W]=-R \#$.

All wine is consumed. Also, French and German initial GDPs are equal. This gives

A5. $W^{\wedge}=\phi C_{W F}^{\wedge}+(1-\phi) C_{W G}^{\wedge}$.

The analogous material balance equation for toys is redundant. We substitute $A 1$ into $A 3$ to eliminate $C_{T F} \wedge$, and $A 2$ into $A 4$ to eliminate $C_{T G}{ }^{\wedge}$. Then we substitute the resulting two equations into $A 5$ to yield

A6. $(1-\phi) W^{\wedge}=(1-2 \phi) R \#+P^{\wedge}(1-\phi)[2 \phi(\sigma-1)+1]$.

The proportional change in French utility equals the proportional change in French wine output minus the transfer as a proportion of French output minus initial French imports as a proportion of French output times the proportional change in the price of toys (the terms of trade effect): 
A7. $U_{F}^{\wedge}=W^{\wedge}-R \#-(1-\phi) P^{\wedge}$.

The proportional change in German utility is the sum of the transfer and its terms of trade effect:

A8. $U_{G}^{\wedge}=R \#+(1-\phi) P^{\wedge}$.

In the full employment case, $W^{\wedge}=0$, so substituting this into $A 6$ yields equation 1 . Then substituting 1 into $A 7$ and $A 8$ yields equations 2 and 3.

In the lump sum tax case, the French wage rate is constant measured in wine. The only way to keep the French real wage constant is to set $P^{\wedge}=0$. Substituting this into $A 6$ yields 6 . Then substituting 5 and 6 into $A 7$ and $A 8$ yields equations 7 and 8 .

When the transfer is financed by the value added tax, $\mathrm{P}^{\wedge}$ is given by 11 . Substituting this into $A 6$ gives equation 12 . Substituting 11 and 12 into $A 7$ yields 13 . Substituting 11 and 12 into A8 yields 14 .

Thus we have solved all three cases.

\section{References}

Beladi, H. (1990). Unemployment and Immiserizing Transfer. Journal of Economics, 52, pp. 253265.

BBC News. 2015. Greece debt Crisis: IMF Attacks EU over Bailout Terms. July 15. http://www.bbc.com/news/business-33531845

J. N. Bhagwati, R. A. Brecher, and T. Hatta. (1983). The Generalized Theory of Transfers and Welfare: Bilateral Transfers in a Multilateral World. American Economic Review, 73, pp. 606618; reprinted in International Trade: Selected Readings, 2nd Edition, Bhagwati, J.N. (ed.), MIT Press, Cambridge. 1987, ch. 27, pp. 431-452.

Bhagwati, J. N., R. A. Brecher, and T. Hatta. (1984). The Paradoxes of Immiserizing Growth and Donor-Enriching "Recipient-Immiserizing" Transfers: A Tale of Two Literatures.

Weltwirtschaftliches Archiv, 120, pp. 228-243.

Bhagwati, J. N., R. A. Brecher, and T. Hatta. (1985). The Generalized Theory of Transfers and Welfare: Exogenous (Policy-Imposed) and Endogenous (Transfer-Induced) Distortions. Quarterly Journal of Economics, 100, pp.697-714. 
Brecher, R. A. and J. N. Bhagwati. (1982). Immiserizing Transfers from Abroad. Journal of International Economics, 13, pp.353-364.

Chichilnisky, G. 1980. Basic Goods, The Effects of Commodity Transfers and the International Economic Order. Journal of Development Economics, 7, pp.505-519.

Chichilnisky, G. (1983). The Transfer Problem with Three Agents Once Again: Characterization, Uniqueness and Stability. Journal of Development Economics, 13, pp.237-248.

The Economist. (2015). Minimum Wages: A Reckless Wager. July 25. p.9.

Friedman, Milton. (1953). The Case for Variable Exchange Rates. In Essays in Positive Economics. University of Chicago Press, Chicago. pp.157-203.

Judd, K.L. (1987). The Welfare Cost of Factor Taxation in a Perfect-Foresight Model. Journal of Political Economy, 95, pp. 675-709.

McKinnon, Ronald I. and Wallace E. Oates. (1966). The Implications of International Economic Integration for Monetary, Fiscal and Exchange Rate Policy. Princeton Studies in International Finance, \# 16. Princeton University Press, Princeton.

Mitchell, Dan. (2010). Keynes Was Wrong on Stimulus, but the Keynesians are Wrong on Just about Everything. September 13. https://danieljmitchell.wordpress.com/2010/09/13/keyneswas-wrong-on-stimulus-but-the-keynesians-are-wrong-on-just-about-everything/

Pettis, Michael. (2013). The Great Rebalancing: Trade, Conflict, and the Perilous Road Ahead for the World Economy. Princeton University Press, Princeton.

Pettis, M. (2015). Syriza and the French indemnity of 1871-73. Credit Writedowns, 5 February 2. https://www.creditwritedowns.com/2015/02/syriza-and-the-french-indemnity-of-1871-73.ht

Shoven, J.B. and J. Whalley. (1984). Applied General-Equilibrium Models of Taxation and International Trade: An Introduction and Survey. Journal of Economic Literature, 22, pp. 1007-1051.

Stuart, C. (1984). Welfare Costs of Additional Tax Revenue in the United States. American Economic Review, 74, pp. 352-362.

Warlters, M. and E. Auriol. (2007). The Marginal Cost of Public Funds in Developing Countries: An Application to 38 African Countries. The World Bank. 3 October. http://idei.fr/doc/wp/2007/marginal_cost.pdf.

\footnotetext{
'Thanks to Euston Quah for suggesting the paper and James W. Dean for comments on it.
} 